\title{
A study on Non-Markovian Bulk Arrival and Bulk Service with Multiple Vacations REENA C G ${ }^{1}$ \\ ${ }^{I}$ ASST. PROFESSOR, DEPARTMENT OF BASIC SCIENCE AND HUMANITIES \\ CHRIST COLLEGE OF ENGINEERING, IRINJALAKUDA \\ ( ${ }^{1}$ E mail:reenababu1971@gmail.com)
}

\begin{abstract}
A queue or a waiting line, involves arriving customers who is waiting to be served at one or more service stations, by one or more servers. The term 'customer' may refer, for example, to a machine arriving at an inspection center or to a person arriving at a booking counter in a railway station. Customers are selected for service by certain rule known as queue discipline. The basic characteristics of a queuing system follows systematically (1) The arrival pattern of customer (2) The service pattern of servers (3) The queue discipline (4) The system capacity (5) Number of servers.

If more than one arrival enters the system simultaneously, the input is said to Bulk Arrival. Customer may be served individually or in batches, in case of batch service the service system is called bulk -
\end{abstract}

Keywords - Customer, server, service station, queue discipline, system capacity, number of servers, bulk arrival and bulk arrival system.

\section{INTRODUCTION}

Queuing theory has been developed to provide models for predicting the behavior of a system that attempts to render service for randomly arising demands. There is a wide range of application of queuing models such as assembly lines in production system, the modeling of digital communication message flows through complex networks and application in the fields with respect to programmer scheduling, time sharing and system design. The activity "Operation Research" has become increasingly important in the fact of fast moving technology and increasing complexities in business and industry.

\section{Definition: 1.1}

In most of the queuing model, the arrival pattern is probabilistic or stochastic, where as in some cases the arrival of customers may be deterministic.

Definition: 1.2

The service times may be deterministic or probabilistic. The customer may be served individually or in batches.
The queue discipline is a procedure by which a customer is selected for service from among the set of customers who are waiting for service. The most commonly used queue discipline is the "first in first out" (FIFO) rule. Another queue discipline is the "last in first out" (LIFO) rule.

\section{Definition: 1.4}

The number of customers that can be accommodated both in the queue and at the service center is called system capacity.

Definition: 1.5

The number of servers in a queuing model may be finite or infinite. If the queuing system has only one server, it is called a single server, when the system has a number of parallel servers; it is termed as multi server queuing system.

\section{HISTORY OF O.R}

$\rightarrow$ The ambiguous term O.R was coined during world war-II, when the British Military Management called upon a group of scientists together to apply the scientific approach to the study military operations to win the battle

$\rightarrow$ The effectiveness of O.R in military spread in it to other governments departments and industry since its birth in the 1940's.

In recent years, Operation Research has successfully entered many different areas of research in defense, government services, organizations and industry. Some applications of Operation Research in the functional areas of management:

\section{STATEMENT OF THE PROBLEM}

The activity 'Operation Research' has become increasingly important the fact of moving technology and increasing complexities in business and industry. Operation Research is mainly concerned with techniques of applying scientific knowledge besides the development of science.

\section{OBJECTIVES OF THE STUDY}

Definition: 1.3 


\section{International Journal of Engineering Technology and Management Sciences[IJETMSS]}

Website: ijetms.in Issue:4, Volume No.4, July-2020 DOI: 10.46647/ijetms.2020.v04i04.002

The specific objectives of the study are:-

1) Finance, budgeting and investments

2) Marketing

3) Purchasing, procurement and exploration

4) Personnel

5) Production

6) Research and Development

The performance analysis of bulk arrival queue with random service interruption multiple vacation rule is studied. The model developed incorporates many features simultaneously including

1) Bulk input

2) unreliable server and

3) Priority makes our results applicable to more versatile congestion situation like distribution and services sectors, production and manufacturing system.

A. Finance, budgeting and investment

- Cash flow analysis, long range capital requirements, divided policies, investment portfolios.

- Credit policies, credit risks and delinquent account procedures.

- Claim and complaint procedure.

B. Marketing:

- Product selection, timing, competitive actions.

- Advertising media with respect to cost and time.

C.Purchasing, procurement and exploration:

- Rules of buying

- Determining the quantity and timing of purchase.

- Bidding policies and vendor analysis

- Equipment replacement policies.

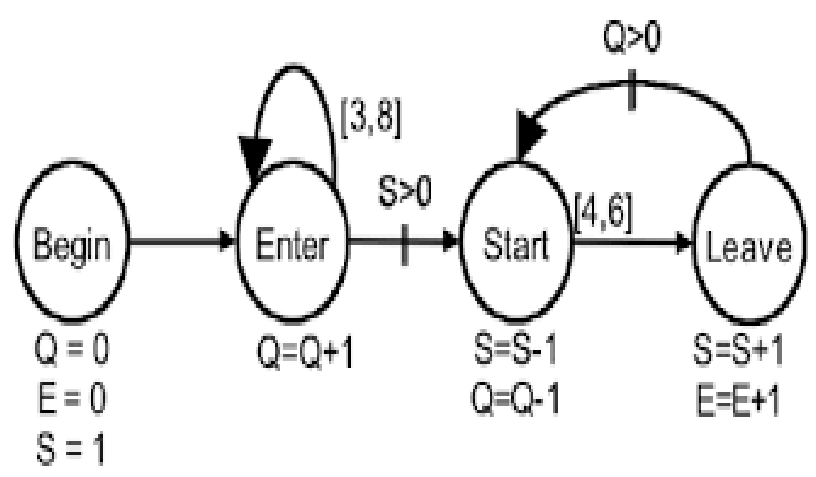

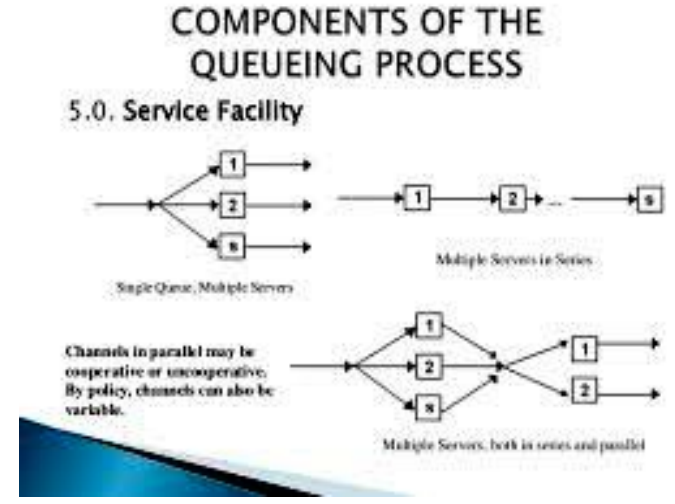

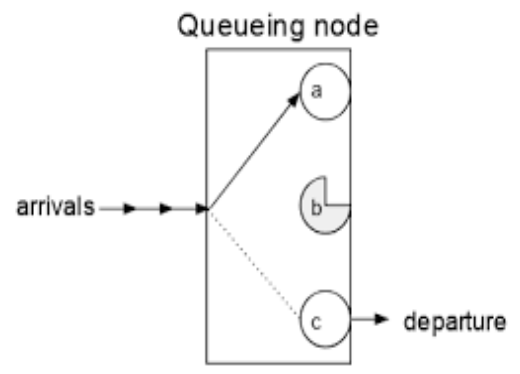

\section{ANALYTIC TECHNIQUE FOR MODELING QUEUING PROBLEMS}

Queuing models are broadly classified as Markovian queuing models and Non- Markovian queuing models

A.Markovian queuing models:

If both inter arrivals time of customers and the service time follow exponential distributions, then the queuing model is said to be Markovian. Markovian queuing models are generally solved by using either difference differential equation method or Neuts matrix -geometric algorithm.

B. Non-markovian queuing models:

Though it is convenient to assume the exponential probability distributions, this may not always be realistic. These are situation is which Markov assumption fail. Queuing system having inter arrival times and or service times which are not exponentially distributed are known as Non-Markovian Queues.

C.Supplementary variable technique:

Some Non - Markovain Models can be analyzed by converting them into Markovian model through the introduction of one (or) more variables. This is known as supplementary variable technique. 


\section{International Journal of Engineering Technology and Management Sciences[IJETMSS]}

Website: ijetms.in Issue:4, Volume No.4, July-2020 DOI: 10.46647/ijetms.2020.v04i04.002

\section{CONCLUSION}

The performance analysis of bulk arrival queue with random service interruption multiple vacation rule is studied. Such system is frequently encountered in practices and in particular, the service oriented operations. PGF of queue size distribution at an arbitrary time is obtained. Explicit formulae for the queue length and expected waiting time have been found. The LST of waiting time distribution has also been obtained. The model developed incorporates many features simultaneously including (i) bulk input (ii) unreliable server and (iii) priority, which makes our results applicable to more versatile congestion situations like distribution and service sectors, production and manufacturing systems.

\section{References}

[1]. Arumuganathan R and Jayakumar S, Analysis of a Bulk Queue with Multiple Vacations and closedown times, International journal of information and management sciences, Vol 15, No.1, (2004), 4

[2]Choudhury G. A batch arrival queue with vacation time under single vacation policy, computers and operations research 29, (2002), 1941-1955, 55-60

[3]Donald Gross, Carl M. Harris, Fundamentals of queuing theory third edition. Wily-interscience publication.

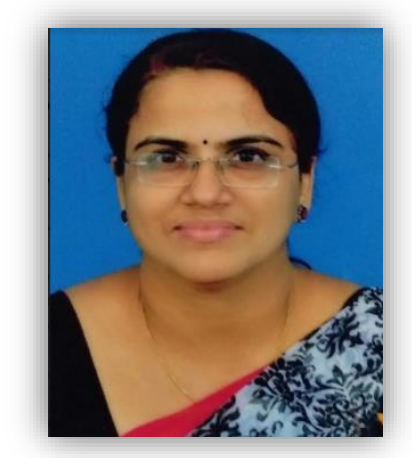

Myself: Reena C G ,Asst. professor in Mathematics, Department of Basic Science and Humanities ,Christ college of engineering, Irinjalakuda ,Kerala, having teaching experience of more than 20 Years. The above study was conducted during my M.Phil. Course from Bharatiar University, Tamil Nadu. 